\title{
Introduction: special issue dedicated to the memory of Professor Daniel Hogan
}

\author{
Roberto Luiz do Carmo • Eduardo Marandola Jr. • \\ Alex de Sherbinin
}

One cannot fully understand the importance of Daniel Hogan's work and his larger legacy without first appreciating the factors that shaped his life. As a graduate student at Cornell University in New York, he traveled to Brazil for his dissertation research. He fell in love with the country and decided in 1973, together with his wife Roseanne, to begin his academic career at what was then a little known university in São Paulo state, the University of Campinas (Unicamp). In many ways, his career mirrored the growth and rising prominence of Unicamp and the Campinas metropolitan area as a center of knowledge and technology. His influence on Brazilian demography and environmental concerns was marked. By the same token, Brazil's rapid economic and demographic growth, together with its environmental challenges, greatly influenced his work and shaped his greatest contributions.

\section{R. L. do Carmo}

Demography Department, Institute of Philosophy and Human Sciences, University of Campinas, Campinas, São Paulo, Brazil

\section{R. L. do Carmo $(\bowtie)$}

Population Studies Center, University of Campinas (Nepo/Unicamp), Ave. Albert Einstein, 1300, Cidade Universitária Zeferino Vaz, Postal Box 6166, Campinas, São Paulo 13081-970, Brazil e-mail: roberto@nepo.unicamp.br

E. Marandola Jr.

School of Applied Sciences (FCA), University of Campinas (Unicamp), Rua Pedro Zaccaria, 1300, Limeira, São Paulo, Brazil

e-mail: eduardo.marandola@fca.unicamp.br

URL: http://www.fca.unicamp.br

\section{A. de Sherbinin}

Population-Environment Research Network (PERN), Center for International Earth Science Information Network (CIESIN), The Earth Institute, Columbia University, P.O. Box 1000

(61 Route 9W), Palisades, NY 10964, USA

e-mail: adesherbinin@ciesin.columbia.edu

URL: http://sedac.ciesin.columbia.edu; www.ciesin.columbia.edu 
Daniel taught at Unicamp for more than 37 years, helping to establish and consolidate the Population Studies Center (Nepo) and Environmental Studies Center (NEPAM). He ultimately was promoted to the position of Vice President for Undergraduate Affairs at the university. Reflecting his interdisciplinary orientation, Daniel mentored more than 20 masters students and 20 doctoral candidates in the fields of Sociology, Demography, Geography and Environment and Society. He was a tireless teacher and an attentive advisor, also working with over 80 undergraduate students. A prolific writer as well, Daniel crafted more than 40 scientific papers, 14 books and edited volumes and over 50 book chapters.

As an overarching accomplishment, Daniel helped establish populationenvironment studies in Brazil and Latin America. His entire career was dedicated to building and strengthening this area of knowledge, both in terms of its theoretical and methodological dimensions and also through its representation within institutional settings.

This issue of Population and Environment provides a small sample of research that was influenced by Professor Daniel Hogan. Many of the main areas of his research agenda are represented within these pages-integrated population and spatial data, urban environmental issues, risks and vulnerability, health and population-environment relationships, migration and land cover and land cover change. Appropriately, many of the contributing authors are former graduate students or were academic collaborators.

Daniel's influence goes well beyond Brazil, however, as he was active in the International Union for the Scientific Study of Population (IUSSP), the International Geographical Union (IGU), and the International Human Dimensions Programme on Global Environmental Change (IHDP). He also served on the founding steering committee of the Population-Environment Research Network (PERN) and on Population and Environment's Editorial Board.

The relationship between population and environment goes to the heart of social dynamics. The field encompasses considerations of equality and equity in light of environmental risks and vulnerabilities. Studies of population-environment dynamics also illuminate how humanity can face new risks. Daniel believed that the study of population and environment relationships could help point the way from the largely negative realm of risks and vulnerabilities to new forms of social organization characterized by greater respect for both the natural world and humanity. It is with this spirit that we dedicate this collection to the memory of Professor Daniel Hogan. 